\title{
Consumer preferences for front-of-pack calories labelling
}

\author{
Ellen van Kleef ${ }^{1, *}$, Hans van Trijp ${ }^{1}$, Frederic Paeps ${ }^{2}$ and Laura Fernández-Celemín ${ }^{3, *}$ \\ 'Marketing and Consumer Behaviour Group, Department of Social Sciences, Wageningen University, \\ Hollandseweg 1, $6706 \mathrm{KN}$ Wageningen, The Netherlands: ${ }^{2}$ FPA Market and Management Advice, Voortstraat \\ 36, 1910 Kampenhout, Belgium: ${ }^{3}$ European Food Information Council (EUFIC), Rue Guimard 19, 1040 \\ Brussels, Belgium
}

Submitted 18 October 2006: Accepted 21 March 2007: First published online 2 July 2007

\begin{abstract}
Objective: In light of the emerging obesity pandemic, front-of-pack calories labels may be an important tool to assist consumers in making informed healthier food choices. However, there is little prior research to guide key decisions on whether caloric content should be expressed in absolute terms or relative to recommended daily intake, whether it should be expressed in per serving or per $100 \mathrm{~g}$ and whether the information should be further brought alive for consumers in terms of what the extra calorie intake implies in relation to activity levels. The present study aimed at providing more insight into consumers' appreciation of front-ofpack labelling of caloric content of food products and their specific preferences for alternative execution formats for such information in Europe.

Design: For this purpose, eight executions of front-of-pack calorie flags were designed and their appeal and information value were extensively discussed with consumers through qualitative research in four different countries (Germany, The Netherlands, France and the UK).

Results: The results show that calories are well-understood and that participants were generally positive about front-of-pack flags, particularly when flags are uniform across products. The most liked flags are the simpler flags depicting only the number of calories per serving or per $100 \mathrm{~g}$, while more complex flags including references to daily needs or exercise and the flag including a phrase referring to balanced lifestyle were least preferred. Some relevant differences between countries were observed. Although participants seem to be familiar with the notion of calories, they do not seem to fully understand how to apply them. Conclusion: From the results, managerial implications for the design and implementation of front-of-pack calorie labelling as well as important directions for future research are discussed.
\end{abstract}

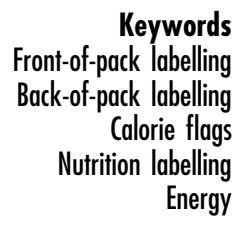

The revealing of information on the nutritional properties of foods can be an important means of reducing the information asymmetry between consumers and suppliers of food products ${ }^{1}$. After all, nutrients cannot be seen, tasted or directly experienced by the consumer. They are the so-called credence qualities of the food product ${ }^{2}$ for which consumers rely on information to be able to make an assessment and comparison. As a result, nutrition labelling information about the nutrient content and sometimes even the nutritional desirability of foods has received considerable attention in recent years. The US Nutritional Labelling and Education Act (NLEA), which went into effect in 1994 and requires most food products to carry a nutrition facts panel, has been one of the landmarks in nutrition labelling policy. Also in Australia and New Zealand, nutrition labelling is mandatory. In the European Union (EU), nutrition labelling is currently not compulsory unless a nutrition claim is made $^{3}$. However, there are countries, like the UK, where most pre-packed products carry nutrition information on labels.

Nutrition labelling, if applied correctly and if adequately used, understood and trusted by the consumer, can assist consumers in taking into account the nutritional content of the food product in their purchase decisions and consequently in making informed choices for healthy options and hence for a more healthy $\operatorname{diet}^{4-6}$. Also, it contributes to consumer protection, as transparency offers consumers their right to know the nutrient content of a food very much like the food's country of origin or its sell-by date ${ }^{7}$. However, it is important to note that although nutrition labelling communicates important information to the consumer, there are no scientific data that convincingly show that nutrition labelling improves dietary patterns. Such evidence is largely confined to 
self-reported measures often collected under controlled situations, which casts doubt on their generalisation to real-life food choice conditions ${ }^{7,25}$. An extra difficulty would be the fact that consumers also eat foods that are not labelled, for example, while eating outside home.

A recent review on consumer understanding of nutrition labelling ${ }^{7}$ has identified lack of time, concerns about accuracy of the information as well as difficulty in understanding the information as among the prominent reasons why consumers fail to use the nutritional information in their actual food choice behaviour. Many consumers report that they find the information confusing and have difficulty in translating the information into actual food choices ${ }^{8}$.

Partly as a result of consumers' inability or lack of motivation to consider the nutritional information as contained in nutrition labels on the back of packs, several parties have suggested to bring the essential information to the front of the packs in order to generate higher awareness and consideration from the consumer. These so-called 'food information programmes' aim at simple logos that highlight foods with nutritional characteristics that aid in promoting health or reducing disease risk. Several of such schemes have been proposed, such as Pick the Tick (since 1989 in Australia and New Zealand), Green Keyhole (since 1989 in Sweden), Heart Check (since 1995 in the USA) and Health Check (since 1998 in Canada). These schemes have in common that they categorise food products into nutritional quality on the basis of nutrient criteria. Also, in Europe, there has been increasing interest in nutritional signposting largely initiated by the UK Department of Health and studies conducted through the Food Standards Agency (FSA). In a series of qualitative and quantitative studies ${ }^{10,11}$, FSA finds that consumers would prefer multiple traffic lights and colour-coded guideline daily amounts (GDA) formats over single traffic lights, which would only indicate the overall healthiness of the product rather than its content on specific nutrients. The debate is still ongoing as to the appropriateness of colour coding (red, amber, green) of individual foods, the expected impact of signposting initiatives, and the preferred format for such information $^{12,13}$. Many consumers limit their information search to the front label ${ }^{14,15}$. When examining health claims, Wansink ${ }^{16}$ found that combining short health claims on the front of a package with full information on the back of the package leads consumers to better understand and have higher trust in the information. This finding implies that using two sides of a package increases the credibility of information and hence it will contribute to consumers' ability to make better choices.

Previous research has focused strongly on the provision of information about the content of specific nutrients. The 'food information programmes', including FSA's signposting scheme, have excluded the amount of calories as an explicit piece of information to the consumer.
This is because from the caloric content of an individual food, it is much more difficult to categorise or qualify (i.e. colour code) the food as healthy or unhealthy. However, if the caloric content is used relative to recommended daily energy intake, such information can be meaningfully provided and this might explain why calories are part of the GDA scheme as put forward by several food manufacturers and retailers ${ }^{12}$.

From a public health perspective, transparent and consumer friendly calorie labelling is a high priority. Over 300 million adults worldwide are obese, according to the latest statistics from the World Health Organization (WHO) and the International Obesity Task Force (IOTF). About one-quarter of the US adult population is said to be obese, with rates in Western Europe on the rise although not yet at similar levels ${ }^{17}$. Although many factors including genetic, environmental and behavioural factors contribute to obesity ${ }^{18}$, dietary factors and physical activity patterns are the major modifiable factors. In the end, obesity is caused by a positive energy balance, i.e. when calories consumed exceed calories expended. Consumers could be aided to maintain a neutral, or even negative, energy balance by providing them with easy to understand and easy to process information on the caloric content of the food products they consume. Several consumer studies on the most frequently looked-at information on food labels in Europe also reveal that calories are always among those on top of the list $\mathrm{t}^{7,10,11,19}$. Calories are the most widely used nutritional indicator and the best established notion with European consumers $^{8,20}$. Still, only very few consumers would really know how to apply the energy notion $n^{7,8,21,22}$ or estimate their recommended daily caloric intake ${ }^{20,23}$.

In summary, in addition to nutrient quality, the amount of calories present in individual foods is a crucial piece of information for the consumers in order to help them make informed choices in their diet. A key challenge for nutrition labelling is to find accurate, yet simple, representations of the caloric information in a format that is appealing, easy to process and easy to understand for consumers. Unfortunately, there is little guidance from prior research into how such caloric labelling should look like. As with other nutrients there is still a lot of discussion as to whether caloric content should be expressed in absolute terms or relative to recommended daily intake, whether it should be expressed in per serving (per portion)* or per $100 \mathrm{~g}$ and whether the information should be further brought alive for consumers in terms of what the extra calorie intake implies in relation to activity levels. The present study aimed at providing more insight into consumers' appreciation of and engagement towards

\footnotetext{
*Note incidently that, although not the focus of this paper, other formats are also possible such as Nabisco's 100 calorie pack which expresses caloric content not in calories per portion but rather as portion of $100 \mathrm{kcal}$.
} 
front-of-pack labelling of caloric content of food products and their specific preferences for alternative execution formats for such information. For this purpose, eight executions of front-of-pack calorie flags were designed and extensively discussed with consumers in four different European countries in terms of their appeal and information value. To enhance market realism, the frontof-pack labels were subsequently also presented to the consumer in the context of a standard back-of-pack nutrition information panel.

\section{Methodology}

\section{Stimuli}

A set of eight front-of-pack flags, all focusing on energy, was specifically designed for this study. These front-ofpack flags (shown in Table 1) differ to the extent that they express the amount of calories in per serving or per $100 \mathrm{~g}$, whether they relate to daily energy needs, and whether they relate to the amount of physical activity necessary to spend the calories ingested. In addition to the front-ofpack labels, back-of-pack nutrition labels were also included in the study. These back-of-pack labels were the current 'standard' nutrition labels, but with a added-on front-of-pack calorie flag and a reference to a help website. The actual content of the nutrition labels was left untouched.

All flags were tested with consumers on (varying) food products (mounted two-dimensional images were used to test the concepts) currently available in the national market place to enhance the task realism. Each flag concept was shown to the respondent having been integrated onto three different food packages, one of which was always Philadelphia Light. The other two food products were selected to represent a mix of well-known brands in various product categories (e.g. breakfast cereals, drinks, snacks, meal components). Care was taken that the food products comprised a mix of low- and highcalorie products (e.g. Coke light and olive oil).

\section{Procedure}

A total of 12 focus groups were conducted, three in each of the following countries: France, Germany, the UK and The Netherlands. Each focus group consisted of 8-10 consumers and lasted approximately $2.5-3 \mathrm{~h}$. All focus groups were conducted in specialised research locations and facilitated by a moderator from a commercial market research agency, specialised in focus groups research. Data were collected in Paris, Chaem (Greater London), Hamburg and Amsterdam.

\section{Respondents}

The respondents were recruited according to a set of sociodemographic criteria as well as their self-reported usage of nutrition labelling. In each country, separate focus groups were set up for young adults (18-24 years old), families (25-55 years old with children in the age group 4-18 years old) and empty nesters (over 55 years old). Each of the groups was composed in such a way that $50 \%$ were self-reported regular users of nutrition labels and $50 \%$ were occasional, $50 \%$ were female, $50 \%$ were professionally active and all were sampled from social classes B, C1, C2 and D. In the family groups, 50\% had children younger than 12 years and 50\% had children older than 12 years.

\section{Protocol}

All focus groups were conducted following the same protocol (see Appendix for the detailed interview guide). The focus group discussions were organised around four key themes. After a short introduction, the respondents discussed their opinions on healthy eating $(15 \mathrm{~min})$ as a warm up, before they discussed the role of nutritional information in general and front-of-pack information more specifically $(35 \mathrm{~min})$. After this initial discussion, respondents were shown the concepts (front-of-pack flags) one by one and asked to individually write down their personal first reactions. They provided an overall liking score (on 1-10 scale) and wrote down their likes and dislikes about each execution. After collecting these initial individual quantitative responses, the respondents shared and discussed their responses in the group for each of the flags consecutively. They were probed further to express and share thoughts on understanding, communication value and credibility of the different flags. Subsequently, each front-of-pack flag was discussed to get a deeper insight of specific elements such as understanding of the calories concept, and preference for labelling in per portion vs. per $100 \mathrm{~g}$. Once all executions were discussed (order differed across focus groups), the respondents individually voted the three best front-ofpack concepts by writing short comments for each of their three top flags. These ratings were then shared and discussed in the group and a group judgement was developed on the preferred flag concept. After the frontof-pack flag evaluations, participants were asked to comment on the labels in the context of a back-of-pack nutrition information panel. The current 'standard' nutrition tables were shown as appearing on existing products, but with addition of the front-of-pack calorie flag and a reference to a help website. The actual content of the nutrition tables was left untouched (see Fig. 1 for an example). At the closing down of the session, the respondents were asked to share their final messages. They were then thanked for their participation.

\section{Data collection and analysis}

Discussions were videotaped and transcribed. During the focus group discussions, reflective notes were taken by 


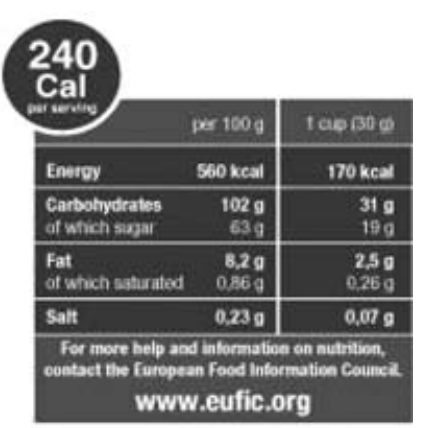

Fig. 1 Back-of-pack nutrition label including a repetition of the front-of-pack calorie flag

an observer. Transcriptions of the focus group discussions were analysed by two researchers to identify broad themes. Individual ratings (marks) on the different executions were analysed in an analysis of variance (ANOVA) procedure with front-of-pack executions, country and their interaction as factors. Qualitative information was content analysed around the key topics of discussion: (1) healthy eating and nutritional information, (2) individual preferences for the front-of-pack executions, (3) opinions, strengths and weaknesses of each of the executions and (4) discussion in the context of back-of-pack nutrition information panel.

\section{Results}

The results will be organised around the four key themes of the interview protocol.

\section{The role of nutritional information and labels}

In terms of health and nutrition information, participants stated that they rely on a combination of sources among which the media (newspapers, television and women's magazines) is highly influential. Many participants claimed to use nutrition labels and that they use product labels when purchasing new products but not very often for regularly bought products. While many participants stated that food labels are very useful, some indicated that they sometimes feel confused in interpreting the food labels and have difficulties in trying to understand this information. This is particularly caused by the terminology used on food labels, which is perceived to be too technical and advanced.

Participants across all focus groups understood what calories are ('it is fuel for the body'). Calories are seen as relevant information to be highlighted on the front-offood packages, as they are seen as summing up the nutritional value of a product and useful for weight loss. It is the measure that most participants felt able to work with, although sometimes with a little help in the form of additional information or reference tables. However, very few individuals could quite accurately state daily needs and their own consumption, while most of the others had absolutely no idea.

Participants were generally positive about front-ofpack calories flags and recognise a variety of benefits. Calorie flags are seen as innovative because the flag is on the front of the package, in contrast to nutrition information which is typically 'hidden' on the back, side or the bottom of a package. In addition, it was mentioned that these flags would encourage them to eat healthier and are seen as a good step in the right direction. Putting the number of calories at the front label allows for more easy comparisons in the store when selecting food products with the lowest amount of calories. In this way, flags can save valuable consumer time:

I would more than likely do a first selection on the basis of what is on the front.

(UK participant)

It is a lot better than what we have now. It is all there, and easy to understand.

(Dutch participant)

In relation to this, it was argued by most participants that flags should be recognisable and consistently used across products.

However, participants also mentioned some concerns. Calorie flags are seen by some as particularly appropriate for people following a calorie-controlled diet. Some participants believed that these labels are only put on 'healthy' products and that mostly women would use them. In addition, a few wondered why only calories were flagged (what about other ingredients like fat and salt?). This was particularly true for some people in the $55+$ group.

Participants generally trust the information on a label, although some participants saw the calorie flags as a promotion tool offered by the manufacturer, similar to front-of-pack claims such as yoghurt with a '0.1\%-fat' label. Several participants described how important it is that the authorities are behind the flags and that the flags are supported by a larger information campaign with a website, billboards and commercials. This will make the system more trustworthy. The campaign should focus on various groups in society, and not only on young people. Participants found it important that the flags are put on the labels to make consumers aware of healthy nutrition and not forced upon them:

The intention should not be to scare us; you should still be able to have your glass of beer and cake every week, because that is part of life.

(Dutch participant)

Overall, the respondents seem to be receptive to front-ofpack calorie-related information as an improvement relative to the current situation. However, a minority of 
Table 1 Participants' evaluations of front-of-pack flags

\begin{tabular}{|c|c|c|c|}
\hline Concept & Characteristics & $\begin{array}{l}\text { Front-of-pack } \\
\text { flag }\end{array}$ & Key factors determining evaluation of flag \\
\hline
\end{tabular}

$1 \quad$ Number of calories per $100 \mathrm{~g}$ of product

2

3

4

5

6

7

8
Calories per serving, portion or per unit (e.g. bar, can)

Calories per serving and daily energy needs for men/women

Calories per serving plus exercise needed to burn those calories (energy in/energy out)
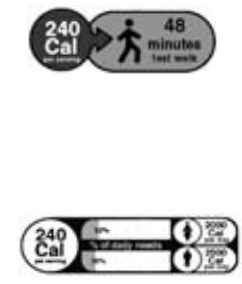

Flag concept 3 plus graphic representation of $\%$ of daily needs $^{*}$

'Full option', i.e. flag concept 5 combined with flag concept 4

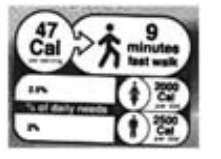

Flag concept 3 plus \% of daily needs* (no graphic representation)

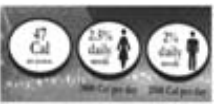

Calories per portion and a phrase referring to healthy eating ('balance your energy')
This flag was generally well liked for its simplicity and clarity. It enables comparison to be made across different product categories. Participants particularly liked the fact that it only shows the most essential information, although they realised that it is difficult to judge how $100 \mathrm{~g}$ relates to portion size

Similarly evaluated as concept 1 , in that it is clear about calories, easy to read, and informative. Some negative remarks related to the fact that it is unclear about the definition of a serving

Daily caloric reference values were considered to be a valuable quick reference to many. The distinction between men and women is considered useful. It is concise information and a reminder of recommended calorie intake per day

This flag is controversial. It is liked by some (especially younger consumers) because they find it easy to understand, and it is motivating to exercise. Most others argue that it focuses too much on health, taking away the pleasure of eating and creating guilt, and not to be taken as serious information (unrealistic and inappropriate)

Liked by some participants for its concise communication of relevant energy information, disliked by others because of its complexity to interpret. The percentage of daily needs was found hard to understand by most participants

Disliked by the majority of participants for being too complex and confusing. Some liked it for its completeness and the fact that there is something in it for everyone. However, they agreed that this was too much information for a front-of-pack label

Disliked by the majority of participants. Too much information which is hard to interpret (particularly percentages)

The simple circle with only the calories is generally well-liked (see concept 2). However, the addition of the sentence 'balance your energy' or similar sentences was seen as meaningless because it takes away the focus from the message. It is seen as a selling gimmick and too coercive

${ }^{*} 2000 \mathrm{kcal}$ is used as general reference for women and $2500 \mathrm{kcal}$ for men.

those who are at specific risk seem to prefer also more specific front-of-pack information on salt and fat.

\section{Consumers' individual ratings of front-of-pack- flag executions}

Consumers' individual ratings on the eight front-of-pack calorie flag executions were subjected to ANOVA with Student-Newman-Keuls multiple comparison test to explore differences between concepts and countries and their interaction. There exist reliable differences in consumer preference between the different front-of-pack executions $(F(1,7)=9.01, P<0.001)$, in overall evaluations between countries $(F=41.70 ; P<0.001)$ and the order of preferred executions differs between countries $(F$ $(1,21)=7.51 ; P<0.001)$. Overall, the most liked concepts are the simpler flags (flags 1 and 2 in Table $1^{*}$ ),

* Order of front-of-pack flags differed between respondents. In what follows, numbering of the executions will be as reported in Table 1. while a more complex flag (flag 7) and the flag including a phrase referring to balanced lifestyle (flag 8) were least preferred (see Fig. 2). Analysis of the marginal means* across countries show that German participants on average rate all executions lowest (marginal mean $=4.0$ ), followed by the UK (marginal mean $=5.4$ ) and French participants (marginal mean $=5.5$ ). Overall, the Dutch participants on average gave higher marks (marginal mean $=6.2$ ). The marginal means of the statistically significant two-way interaction between execution and country are shown in Fig. 2, which show that it is particularly the German consumers' evaluation that deviates from the other countries. German consumers are much more outspoken in that they are slightly more positive about the simpler flags 1 and 2, but substantially more

*Estimated marginal means, also called least-squares means, are means that have been corrected for all other factors in the ANOVA model. They reflect the unique contributions of particular effects. 


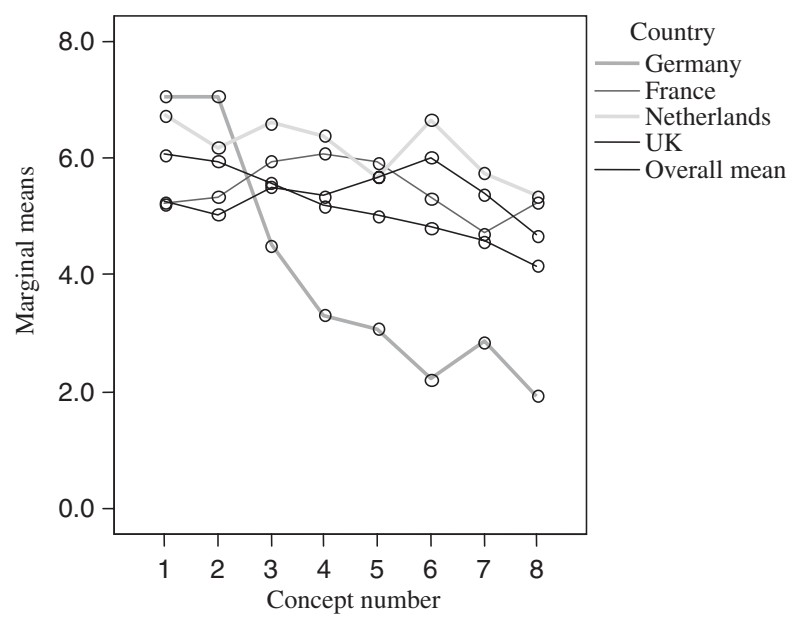

Fig. 2 Mean individual consumer ratings for the flag executions 1-8 (see Table 1) in different countries (Germany, France, The Netherlands and UK)

negative about all the other executions than consumers from other countries.

\section{Detailed comments about the specific executions}

From the discussions with respondents on the more detailed opinions about the various executions, a number of key themes relating to front-of-pack flag evaluations emerged. These included: (1) the amount of information provided in a flag, (2) the assessment of the amount of calories consumed relative to portion size, (3) reference to exercise and (4) the assessment of the relative contribution to the total amount of calories consumed in a day. Results below are categorised according to these four themes and differences between countries are highlighted where appropriate.

\section{Completeness and informative vs. catchy and easy to} understand

The experimentally designed flags differ in the amount of information they provide. More simple flags (in particular flag concepts 1 and 2) were generally liked by the majority of participants. In particular, German participants considered these flags to be very helpful. These flags are considered more easily processed in that they are understandable at first glance. They do not require too much thinking and time to read. This is in contrast to more complete energy flags (such as flag concepts 5, 6 and 7 ), which are perceived as most informative. However, it was clear to the respondents that combining these various types of information is a complex task, even for motivated consumers. Many participants questioned the need to put all information in one flag. When the concept did not allow for quick inspection, participants felt a bit overwhelmed by the number of details and described these flags as too technical and complex. A visual overload may lead to not using the flag in purchase decision making, as indicated by a participant evaluating the flag which included all information (flag 6):

Completely crazy, too much blah-blah. (French participant)

Often mentioned in the discussion was the need for a flag to be catchy and stand out from other information on the package. Being 'catchy' and the ease of their understanding was related by the respondents to design characteristics of the flags, such as legibility and clever use of colour. An older German participant recommended the use of sufficiently large letter sizes so that the flags can be read without reading glasses. Sentences such as 'balance your energy' are typically seen as meaningless because respondents fail to understand what is meant by it. Adding such a sentence was viewed with scepticism by many participants, suspecting that it was simply a marketing tool. This finding is reflected in the low marks that concept 8 received across countries.

Calories per portion size vs. calories per $100 \mathrm{~g}$

As discussed before, participants liked the simple frontof-pack flags only showing calories (concepts 1 and 2) for their clarity and focus on the essentials. Discussion of these two simple flags showed that calories per portion was clearly seen as an instrument to assess the nutritional content of what one was actually buying or consuming, while calories per $100 \mathrm{~g}$ was mostly cited as an instrument for comparison between different choices: 'This allows us to compare' (Dutch participant).

In general, participants found it difficult to understand what a large amount of calories is ('bow much is too much'). Participants were aware of the fact that an amount of $100 \mathrm{~g}$ often does not match the amount typically consumed in one eating occasion. Participants discussed extensively various issues related to the question 'what is a serving (portion) size?' The majority of participants were aware that a serving size is not necessarily a whole package and also not the amount of food that will be eaten. They did, however, wonder how many servings are in a package and how to compare this to the amount actually eaten. It was seen as problematic to some participants that they had to do some calculations to figure out how many calories they will get. If you eat an entire package, you have to multiply the amount of calories by the number of servings in a package size. Some participants wondered whether other meal components are also included (such as the ketchup with French fries).

\section{Referring to exercise}

Physical activity symbols show how much consumers have to exercise in order to burn off the calories in a serving size. Several participants mentioned that referring to exercise made them realise that overweight is also the consequence of lack of exercise. However, respondents 
see the reference to exercise as confronting because it makes them realise how much work it takes to burn off a small amount of calories by walking. This derives from the inherent imprecision of the concept (as it does not take into account the basal metabolic rate energy expenditure). Another downside might be that the awareness effect will wear off after some time. While some participants noted that these symbols could make people more aware of exercise, most participants were sceptical of the effectiveness of this flag:

I do not think that people would walk if they ate a packet of crisps.

\section{(UK participant)}

A key theme in the discussion of this type of flag was that it can be demotivating and patronising. Some participants said that it evoked a feeling of guilt, as the urge to burn off the calories through exercise would not stop them from eating a particular high-calorie food. According to a few participants, flags should focus on the pleasure of choosing and eating foods. In particular, on indulgence foods such as chocolate, these flags were not liked. In France, some participants felt that the picture of the walking man was funny and therefore not to be taken too seriously.

\section{Referring to daily needs}

Concepts 5, 6 and 7 include the percentage of daily energy values. These percentages tell the consumer whether the calories in a serving of a food contribute a lot or a little to the total daily calorie intake. Reference to daily needs was liked by a considerable number of participants, mostly so in the UK and by younger participants. It was considered a quick reference. Most participants did not know their average daily needs and saw this as helpful. It puts the calories in perspective:

Basically, they've told you 47 calories out of 2500 is nothing, so you think that's obviously alright for you. It is still per serving, still a bit tricky, but you can work out I'm not going to kill myself eating that because I can have 2500 .

\section{(UK participant)}

In those flags where the calories contained in a serving of a product were represented as a percentage of daily needs, a few participants were unsure whether the percentage indicated 'a little' or 'a lot'. Some participants were very negative, as knowing that they have had, for example, $13 \%$ of their daily intake would not help them making choices regarding the $87 \%$ left.

When the calories contained in a serving of a product were represented graphically as percentage of daily needs through a bar chart (concepts 5 and 6), certain participants were quite puzzled. Although younger participants liked this flag for its compact communication of all key energy information, to some older participants the flag resembled medical symbols used on medicines, which was seen as too complex. One participant argued that 'supermarkets should not be pharmacies'. Similar to the exercise symbols, participants expressed their concerns that this flag seems to take away the pleasure of eating. One French participant said: 'Eating is not just for surviving, eating is for pleasure.

Flag 7 also shows the percentage daily needs delivered by the product, but without a bar chart. Overall, this option was not preferred by participants as it requires too much interpretation effort by turning food shopping into a mathematics test:

It's a pain really $\ldots$ this is $8 \%$ of what I should be having?

(UK participant)

The pictograms used to express the daily needs for men and women were seen as very helpful and understandable, though probably a bit redundant on a front panel after a while. However, there was much debate about the percentage daily needs referring to some kind of 'average' person's daily needs. A few participants commented that this might not match their own needs, particularly when they have a day with a lot of physical activity. Moreover, some participants could not relate themselves to an 'average' person:

What is average? Am I average?

(German participant)

\section{Evaluation in the context of back-of-pack nutrition information panel}

When evaluating front-of-pack flags in relation to the standard back-of-pack nutrition labels, participants did not change their opinion regarding the calorie flags, although the reappearance of the front-of-pack calorie flag on the nutrition label was seen as a helpful addition by the majority of participants. The advantage of calorie flags on the front of a package is that they allow for a quick comparison between products, while back-of-pack nutrition labels were considered to be particularly appropriate for more interested consumers. In this respect, reference to a website was considered to be useful, as one German participant stated: 'There is no abundant information, as more information can be obtained through the website. In contrast to front-of-pack flags, various participants argued that they do not find it realistic to read the back of a pack all the time: 'I doubt if we would all go round the supermarket reading the back of everything. Participants expected to find more detailed information about the nutritional value at the back of a pack:

You would have on the front what most people look at when they get it out of the fridge or in the shop, and on the back what they want to see when they look at it properly.

(UK participant) 


\section{Discussion}

The main objective of this study was to get insights into the potential of a variety of energy-based front-of-pack flags as motivational tools for consumers towards nutrition information on food labels and nutrition in general.

Our results suggest that highlighting energy on the front of the pack might be a promising platform of communication to the consumer. Consumers see front-of-pack flags as an improvement over current on-pack nutritional information, also when they see them in combination with the back-of-pack nutrition information panel. Our findings confirm that 'energy' and 'calories' are relatively wellestablished notions with the consumers and often considered as a summary measure of nutritional qualities of foods ${ }^{8}$. Participants across all focus groups and countries are aware of calories and see them as a relevant measure to highlight on the front of the pack as they sum up the nutritional value of a product and are useful with weight management. Front-of-pack information was well received and participants felt that having The information on the front would allow them to more quickly and easily compare products while shopping. This is in line with previous research $^{21}$ showing that consumers feel that front-of-pack labelling can help them make healthier choices. For example, the food industry in The Netherlands has implemented front-of-pack energy logos as a means to inform consumers and help them towards managing their diet.

Our results further suggest that in communicating front-of-pack caloric information, many consumers prefer executions that are simple, easy to interpret and use. It seems that the simpler the information provided on the front of the pack, the better the understanding and engagement of consumers. Of the eight front-of-pack flags examined, most participants preferred the simple flags, solely indicating the amount of calories per $100 \mathrm{~g}$ or per serving. The simple flag including references to daily energy needs was also much liked, although there was disagreement on whether this more detailed information should be presented on the front or back of the pack. Previous research already showed that consumers request simplicity regarding nutrition information provided on labels as a key for their understanding and engagement $^{7,8}$. Reference to daily needs has a potential to help consumers put things into perspective ${ }^{19,21}$ but more complete (and hence complex) flags were least preferred.

There were lots of similarities between the different groups tested and across different countries, indicating that energy (calories) might be one good minimum common denominator to work from in future initiatives. However, German consumers proved to have a fairly different perspective from those in the UK, France and The Netherlands. German consumers tend to be much more outspoken in that they show a stronger preference for simple front-of-pack flags than for more complex communication front-of-pack formats.
Overall, our results show that energy-based front-ofpack communication systems hold potential, although several consumer issues or dilemmas need to be addressed when developing and introducing it. A first key dilemma is on how much information to put on a flag. On the one hand, simple flags are well-liked by consumers for their straightforwardness and ease of use. On the other hand, younger consumers in particular appreciate more detailed information, such as their daily energy needs, to be included in the flag as this would help them to put the amount of calories they are eating into perspective. Also, the preferred amount of information seems to differ between countries. UK participants were generally more positive about flags showing daily energy needs and charts showing percentage daily needs delivered by the food product. This preference might be explained by the fact that consumers in this country are more familiar with nutrition information on packages. German participants were negative about everything that was complex and have a preference for the simple flag showing calories per $100 \mathrm{~g}$. This issue is of great importance; in particular, if a labelling scheme was to be proposed for EU-wide usage. Closely related to this issue is that front-of-pack flags should provide information in a consistent way on the front of all packs and not just on products that compare favourably. In this way, consumers will trust the information and will be enabled to learn how to use the information provided by the flags.

A second key consideration is how to choose between flags indicating the amount of energy per serving vs. per $100 \mathrm{~g}$. The calories per serving flag will only be helpful if consumers understand what exactly a serving unit is. It has been found that consumers are not very good at assessing the number of calories in a portion ${ }^{24}$. In our research, consumers found this option as the most preferable as long as the serving represents a realistic and easy-to-understand consumption unit. Otherwise, they would rather have the energy expressed per $100 \mathrm{~g}$, with the exception of the UK, where they found the information per $100 \mathrm{~g}$ unclear, possibly due to the lesser use of the metric system. However, both options seem to fulfil different roles: the calories per serving would give them a realistic perspective on how many calories they are consuming, whereas the calories per $100 \mathrm{~g}$ would allow them to more easily compare products.

Thirdly, when discussing the daily needs, participants felt confused about the meaning of average daily needs, recognising that there may be individual differences also based on energy expenditure. This dilemma could potentially be solved through the development of complementary and supporting educational campaigns on daily energy needs or by providing more detailed complementary information through a link to a reference website.

Fourthly, the reference to exercise on front-of-pack energy flags seems to be polarising. Despite the fact that 
the notion of energy output is key to understanding the energy balance, many participants were sceptical or negative about the flags referring to exercise. This is in line with previous findings that show that consumers feel frustrated when they realise how much effort it takes to burn the amounts of calories in a given food ${ }^{22}$. Most consumers seem to understand the underlying implicit message: increase the level of exercise, but most respondents feel that this sort of information does not belong on the food package. Messaging opportunities should be further explored to find other means to convey the concept to consumers. From our results, it seems that off-pack communication on the notion of energy balance is more appropriate than confronting consumers with it on-pack.

The fifth consideration is if a standarised nutrition labelling system was to be proposed, it should be considered that although there are lots of similarities among different European countries, there are also some differences. Research done by EUFIC ${ }^{8}$ already pointed out the different relationship the UK consumers had with food and nutrition compared to other continental countries (like France, Italy or Germany). The present study reinforces this; for example, the fact that UK participants are more aware of daily needs than their continental counterparts. This should be taken into consideration when suggesting standardised approaches. However, calories are relevant to the present challenge of the obesity epidemic and seem to be the minimum common denominator. Therefore, the energy approach on frontof-pack labels could be the starting point, complemented or not to different extents with other systems, for a European standardised approach. Consumers also like uniformity across food product categories.

Finally, although participants seem to be familiar with the notion of calories, they do not seem to fully understand how to apply it. This is in line with results from $\mathrm{EUFIC}^{8}$ and others $^{7,22}$. The lack of understanding on calorie application is among the main barriers to an effective use of nutrition information on food labels ${ }^{23}$. Increasing the nutrition knowledge increases the likelihood of nutritional label usage and has a positive effect on the quality of the consumer's diet ${ }^{4-6}$. To be successful, any initiative aimed at helping consumers to understand and use the nutrition information on food labels is likely to require a concurrent consumer education and marketing strategy to be developed. The strategy should be adapted to specific population groups (e.g. non-users of the label, male, socio-economically disadvantaged and people with lower education). In parallel, certain issues such as the technical terminology or the information complexity (e.g. percentages or graphs, serving sizes per $100 \mathrm{~g}$ ) would need to be resolved to improve the usage and understanding of the nutrition information on food labels.

As a first assessment of consumer appreciation of frontof-pack energy-related flags, this study has a number of limitations. As there was little published research to guide us, we took a qualitative approach to the issues. Qualitative research seems appropriate at this stage as it allows for more in-depth exploration of underlying motivations and considerations on the part of the consumer. However, the qualitative nature of this study, and its inherent restrictions on the number of executions, respondents and countries involved, is a key limitation of this study. Clearly, future quantitative approaches would be required to substantiate these findings in a more representative sample of respondents and broader generalisation across different countries. Such quantitative approach will also allow us to explore individual and cultural differences in preference for different front-of-pack flags and more systematically in more detail.

In summary, even though this study takes a qualitative approach and therefore its results can be neither quantified nor extrapolated to the general population, it has brought insight into consumers' appreciation and understanding of an energy communication platform. Our findings suggest that highlighting energy on the front of the pack is a promising platform of communication. They also suggest that consumers, across different population groups and countries, see added value in front-of-pack energy labelling and prefer simple information on the front of the pack which is substantiated and detailed on the back of the pack, similar to what has been found in the US situation ${ }^{16}$. However, due to the on-pack limitations, there is a need to provide substantiation through education and other communication channels (e.g. a trusted website for reference).

In light of the emerging obesity pandemic, more research is warranted to more specifically figure out how to best convey the concept of energy to different population groups in order to foster their informed food choices. The energy in-energy out relationship should be explained with realistic and practical messages ${ }^{23}$. Messaging opportunities should be further explored if we want to achieve effective educational campaigns and ultimately to change behaviour. Future research looking at means to increase the use of nutrition information of labels during the purchase of products could also help.

\section{Acknowledgements}

Sources of funding: The study was supported by the European Food Information Council (EUFIC).

Conflict of interest declaration: There are no conflicts of interest.

Authorship responsibilities: L.F.-C. (EUFIC) initiated and designed the study. F.P. conducted the focus groups and gathered the data. Data analysis and production of an internal report was done by L.F.-C. with the help of F.P. E.v.K. and H.v.T. analysed further the data and drafted the scientific manuscript. All co-authors made substantial contributions to data analysis and interpretation and the writing of the manuscript. 
Acknowledgements: The authors would like to thank Gwénaëlle Bizet for all her work and help.

\section{References}

1 Verbeke W. Agriculture and the food industry in the information age. European Review of Agricultural Economics 2005; 32(3): 347-68.

2 Darby MR, Karni E. Free competition and the optimal amount of fraud. Journal of Law and Economics 1973; 16: $67-88$.

3 Hawkes C. Nutrition Labels and Health Claims: the Global Regulatory Environment [online]. Geneva: World Health Organization, 2004. Available at http://whqlibdoc.who.int/ publications/2004/9241591714.pdf. Accessed September 2006.

4 Kim S, Nayga RM, Capps O. The effect of food label use on nutrient intakes: an endogenous switching regression analysis. Journal of Agricultural and Resource Economics 2000; 24(1): 215-31.

5 Kim S, Nayga RM, Capps O. Food label use, self-selectivity, and diet quality. Journal of Consumer Affairs 2001; 35(2): 346-63.

6 McLean-Meyinsse PE. An analysis of nutritional label use in the Southern United States. Journal of Food Distribution Research 2001; 32(1): 110-14.

7 Cowburn G, Stockley L. Consumer understanding and use of nutrition labelling: a systematic review. Public Health Nutrition 2005; 8(1): 21-8.

8 European Food Information Council (EUFIC). Nutrition Information and Food Labelling. EUFIC Forum No. 2. Brussels: EUFIC, 2005.

9 Smith SC, Stephen AM, Dombrow C, Macquarrie D. Food information programs: a review of the literature. Canadian Journal of Dietetic Practice and Research 2002; 63(2): 55-60.

10 Food Standards Agency (FSA). Qualitative Signposting Labelling Refinement Research [online]. Research carried out by Synovate for FSA. London: FSA, November 2005. Available at http://www.food.gov.uk/multimedia/pdfs/ signpostqualresearch.pdf. Accessed September 2006.

11 Food Standards Agency (FSA). Quantitative Evaluation of Alternative Food Signposting Concepts [online]. Research carried out by Synovate for FSA. London: FSA, November 2005. Available at http://www.foodstandards.gov.uk/multimedia/ pdfs/signpostquanresearch.pdf. Accessed September 2006.

12 Bussell G. Nutritional profiling vs. guideline daily amounts as a means of helping consumers make appropriate food choices. Nutrition and Food Science 2005; 35(5): $337-43$.

\section{Appendix - Interview guide}

1. Introduction ( $5 \mathrm{~min}$ ) explains objectives of group discussion and rules of interaction.

(a) Tour de table to get to know each other.

2. Warming up: Nutrition and healthy eating (15 min).

(a) Objective:

(i) Set the framework and check consumer perceptions of the world of nutrition information.

(b) Method:

(i) Associations with food, nutrition and emotions with food.
13 Denny A. Stop, think, go? - are signposting labelling schemes the way forward? British Nutrition Foundation Nutrition Bulletin 2006; 31: 84-7.

14 Levy AS, Fein SB. Consumers' ability to perform tasks using nutrition labels. Journal of Nutrition Education 1998; 30: 210-17.

15 Roe B, Levy AS, Derby BM. The impact of health claims on consumer search and product evaluation outcomes: results from FDA experimental data. Journal of Public Policy and Marketing 1999; 18(1): 89-105.

16 Wansink B. How do front and back labels influence beliefs about health claims? Journal of Consumer Affairs 2003; 37(2): 305-16.

17 International Obesity Task Force (IOTF). Available at http:// www.iotf.org. Accessed August 2006.

18 Martinez JA. Body-weight regulation: causes of obesity. Proceedings of the Nutrition Society 2000; 59(3): 337-45.

19 Institute of Grocery Distribution (IGD). Guideline Daily Amounts Consumer Research Report [online]. Watford: IGD, 2004. Available at www.igd.com/gda. Accessed September 2006.

20 safefood - the Food Safety Promotion Board. Safetrack 3. Consumer Tracking Research [online]. Co. Cork: safefood, October 2004. Available at http://www.safefoodonline.com/ Uploads/121104\%20safetrak\%203\%20FINAL.pdf. Accessed September 2006.

21 Bureau Européen des Unions de Consommateurs (BEUC). Report on European Consumers' Perception of Foodstuffs Labelling [online]. Brussels: BEUC, August 2005. Available at http://www.spismest.dk/NR/rdonlyres/1BF5B95B-3B4D4138-B806-61DAFD0E4F20/0/20050069201E.pdf. Accessed September 2006.

22 International Food Information Council (IFIC) Foundation. Food Label \& Calorie Research: Qualitative Research Findings [online]. Washington, DC: IFIC Foundation, August 2004. Available at http://www.ific.org/research/upload/ Calorie_Qualitative_Research.pdf. Accessed September 2006.

23 International Food Information Council (IFIC) Foundation. Food and Health Survey: Consumer Attitudes toward Food, Nutrition \& Health [online]. Washington, DC: IFIC Foundation, 2006. Available at http://www.ific.org/research/ upload/2006foodandhealthsurvey.pdf. Accessed September 2006.

24 Wansink B, Chandon P. Meal size, not body size, explains errors in estimating the calorie content of meals. Annals of Internal Medicine 2006; 145(5): 326-32.

25 Grunert KG, Wills JM. A review of European research on consumer response to nutrition information on food labels. Journal of Public Health 2007; in press.
3. Nutrition labelling on pack (35 min).

(a) Objective:

(i) Set the framework and consumer' realities of on-pack nutrition information.

(b) Method:

(i) Spontaneous associations with the term 'on-pack nutrition information' and its meaning and use.

(ii) Word associations with nutritional labelling.

4. Nutrition labelling proposals: individual responses.

(a) Objective:

(i) Collect consumer perspective on the various front-of-pack (f-o-p) proposals. 
(b) Method:

(i) Show first concept and hand out evaluation sheet for participants to record individual reaction first (overall score as school rating 1-10) and to write down individual likes and dislikes with the concept.

(ii) Repeat for each of the other concepts.

(iii) Then show the back and collect feedback.

(iv) Then collect input on combination of front and back.

5. Nutritional labelling proposals: group discussion.

(a) Objective:

(i) Group level discussion and further probing.

(b) Method:

(i) Show first concept and discuss in group the likes and dislikes.

(ii) Probe specific understanding on meaning of calories and expression per $100 \mathrm{~g}$.

(iii) Then continue for other (f-o-p) concepts.

(iv) Repeat for back side labels.

(v) Repeat for back and front side labels together.
6. Selection of winning concepts.

(a) Objective:

(i) Selection of winning concepts.

(b) Method

(i) Allow participant to revise scores (on 1-10 scale) for the f-o-p labels. Then let participants vote their three best concepts by writing short comments for each of their three top flags.

(ii) Then discuss in group which ideas to keep and which to withdraw plus and explanation.

(iii) Further discuss preference for referencing to website.

7. Final message.

(a) Objective:

(i) Closing down the session.

(b) Method:

(i) Write down final message and comments one wants to share.

(ii) Close session by thanking respondents for participation. 